\title{
Examination of Malignant Findings of Thyroid Nodules Using Thyroid Ultrasonography
}

\author{
Daigo Saito ${ }^{\text {a }}$ Ritsuko Nakajima ${ }^{\text {a }}$, Shigemitsu Yasuda ${ }^{a}$, b
}

\begin{abstract}
Background: It is important to distinguish benign thyroid nodules from malignant thyroid nodules. Hence, this study aimed to determine the characteristics of patients with thyroid cancer using thyroid ultrasonography.
\end{abstract}

Methods: We retrospectively examined the ultrasonographic findings of 327 patients with 457 thyroid nodules (age: $59.9 \pm 14.3$ years; sex, n (\%): female $242(74.0 \%)$ ) at a single center from 2014 to 2016. Ultrasonography was used to determine the nodule size, shape, border, internal echogenicity, presence of coarse calcifications and microcalcifications within the nodule, internal blood flow and whether the nodule was solid or contained cystic structures. Thyroid fine needle aspiration cytology (FNAC) was performed in all patients. The ultrasonographic findings were compared between patients with benign nodules and those with papillary thyroid carcinoma (PTC). Furthermore, in the analysis of anti-thyroglobulin $(\mathrm{Tg})$ antibody-negative patients with single nodules, values of serum $\mathrm{Tg}$ /nodule volume were calculated and compared between patients with benign nodules and those with PTC.

Results: There were 298 (65.2\%) benign nodules, 33 (7.2\%) PTCs and $126(27.6 \%)$ others (104 follicular neoplasms, 19 masses of undetermined significance and three other malignant tumors). The nodules diagnosed as PTC had significantly lower internal echogenicity $(\mathrm{P}<$ $0.01)$, more microcalcifications $(\mathrm{P}<0.01)$ and comprised more nodules rich in blood flow $(\mathrm{P}<0.05)$ than benign nodules. Solid nodules were found significantly more in the PTC group $(\mathrm{P}<0.01)$. The serum $\mathrm{Tg} /$ nodule volume ratio was significantly higher in the PTC group ( $\mathrm{P}$ $<0.05)$.

Conclusions: Findings suggestive of PTC were found from images obtained using thyroid ultrasonography. In the diagnosis of PTC, the frequency of FNAC examinations should be reduced as this method is costly and invasive.

Manuscript submitted June 10, 2020, accepted June 30, 2020

Published online July 22, 2020

aDepartment of Endocrinology and Diabetes, Saitama Medical University, Iruma-gun, Saitama 350-0495, Japan

${ }^{b}$ Corresponding Author: Shigemitsu Yasuda, Department of Endocrinology and Diabetes, Saitama Medical University, Morohongo 38, Moroyama, Irumagun, Saitama 350-0495, Japan. Email: shigemitsuyasuda@msn.com

doi: https://doi.org/10.14740/jocmr4260
Keywords: Ultrasounds; Thyroid nodule; Thyroid papillary carcinoma; Internal echogenicity; Microcalcification; Thyroglobulin

\section{Introduction}

Recently, an increasing number of patients are found to have thyroid nodules accidentally by computed tomography (CT) examination, magnetic resonance imaging (MRI) examination and carotid ultrasonography [1]. Traditional screening for nodular thyroid disease is palpation during screening [2]. However, screening has recently been conducted using an ultrasound system [1].

In a study of human subjects, it has been reported that thyroid ultrasound showed thyroid nodules in $22.8 \%$ of patients [3]. Most of these thyroid nodules were benign, and only a few were malignant nodules. Therefore, in the treatment of thyroid nodule lesions, it is important to properly diagnose and distinguish malignant thyroid nodules from other thyroid nodules. Thyroid ultrasound is cheaper and simpler than CT and MRI, and is the primary tool for diagnosing thyroid diseases as it is noninvasive. In recent years, with the improvements in the resolution of ultrasonography equipment, it has become possible to diagnose nodules of several millimeters, and the number of thyroid ultrasound examinations performed has increased accordingly. As a result, many thyroid nodules are discovered and diagnosed, and the high incidence of thyroid nodules is a growing public health concern [4]. The previously reported ultrasound findings useful for differentiating benign from malignant thyroid nodule lesions are fine calcification, borderline obscurity or septate, intranodal blood flow increase, aspect ratio $>1$, solid nodules and hypoechoic nodule findings [5]. In addition, many studies have evaluated the relationship between thyroid cancer and blood thyroglobulin (Tg) concentration. However, it is difficult to distinguish malignant thyroid nodule lesions from benign thyroid nodule lesions based only on serum Tg concentration [6]. Previous studies have extensively reported the number of individuals from various countries diagnosed with thyroid nodule lesions, mainly in the West, and these data are being accumulated. On the other hand, people from Japan have higher iodine intake than those from other countries, and this affects the incidence of thyroid diseases. Hence, the use of existing thyroid disease data remains controversial [7]. Moreover, 


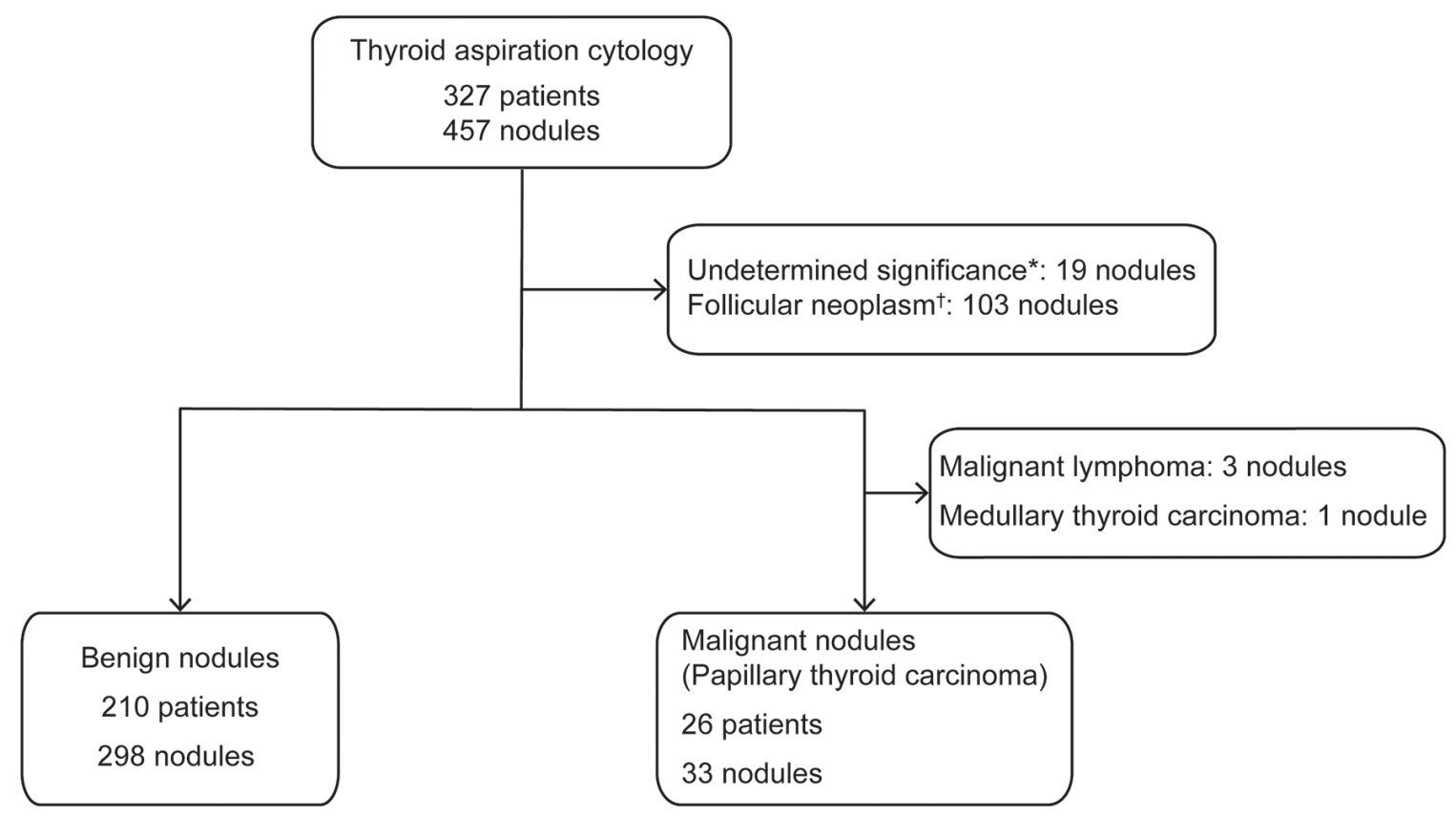

Figure 1. Flow chart of the enrollment process for the malignant and benign nodule groups. *Undetermined significance, falling under "III. Atypia of undetermined significance or follicular lesion of undetermined significance" in the diagnostic category of the Bethesda System. 'Follicular neoplasm, falling under "IV. Follicular neoplasm or suspicious for a follicular neoplasm" in the diagnostic category of the Bethesda System.

the morbidity rate of follicular thyroid carcinoma is lower, while that of papillary thyroid carcinoma is higher, in Japan than in other countries [8].

With regard to differentiating benign from malignant thyroid nodular lesions, none of the previous retrospective studies included multiple specialists performing ultrasound image analysis in a single institution, used identical ultrasound diagnostic devices and investigated the usefulness of serum $\mathrm{Tg}$ values. Careless fine needle aspiration biopsy cytology (FNAC) should be avoided in the diagnosis of thyroid nodules. Therefore, in this study, we aimed to examine the characteristic ultrasound findings of patients with papillary thyroid carcinoma (PTC), which is the most frequent thyroid carcinoma. We also aimed to determine the usefulness of measuring serum $\mathrm{Tg}$ concentration in differentiating benign from malignant nodules.

\section{Materials and Methods}

\section{Study design and patient population}

This retrospective study included 327 patients who underwent FNAC for thyroid nodule lesions at Saitama Medical University Hospital from 2014 to 2016. The institutional review board at our university approved the study (approval number: 17018). All procedures performed in studies involving human participants were in accordance with the ethical standards of the institutional committee and with the 1964 Declaration of Helsinki and its later amendments or comparable ethical stand- ards.

FNAC was performed for 457 thyroid nodules, and the Japanese Society of Thyroid Surgery (RSJSTS) 2015 reporting system [9] was used to differentiate benign from malignant nodules. This reporting system is based on the 2017 Bethesda System for Reporting Thyroid Cytopathology (TBSRTC) [10], and the individual cytological results of this study were finally evaluated against the criteria of TBSRTC [10].

Nineteen nodules were determined to be atypia of undetermined significance or follicular lesions of undetermined significance, while 103 nodules were determined to be follicular neoplasms or suspected follicular neoplasms; these lesions were excluded from the analysis. We also excluded three nodules from patients who had thyroid malignant lymphoma and excluded one suspected medullary thyroid carcinoma. Ultimately, the malignant group (i.e., malignant and suspected malignant lesions) included 26 patients with 33 nodules, while the benign group included 210 patients with 298 nodules (Fig. 1). The malignant nodules were diagnosed as PTC.

Furthermore, we investigated the usefulness of measuring serum $\mathrm{Tg}$ concentration for differentiating benign from malignant thyroid nodules. Serum $\mathrm{Tg}$ concentrations, anti-Tg antibody (TgAb) and anti-thyroid peroxidase antibody (TPO$\mathrm{Ab})$ levels were measured using an electrochemiluminescence immunoassay in all patients in this study (SRL Inc., Tokyo, Japan). In Japan, TgAb and TPOAb levels are used to diagnose Hashimoto's thyroiditis [11], whereby the $\mathrm{TgAb}$ of $\geq 28 \mathrm{IU} /$ $\mathrm{mL}$ and/or TPOAb of $\geq 16 \mathrm{IU} / \mathrm{mL}$ are considered diagnostic of Hashimoto's thyroiditis $[12,13]$. These values are based on the results of a Japanese study, which reported the correlation 
Table 1. Characteristics of Thyroid Nodules on Ultrasonography

\begin{tabular}{ll}
\hline Characteristics of thyroid nodules & \\
\hline $\begin{array}{l}\text { Shape } \\
\text { Boundary property }\end{array}$ & An integer indicates a circle or an ellipse. Irregularity indicates an irregular shape. \\
Boundary clarity & Edge of the lesion is linear (smooth) versus serrated (coarse). \\
Internal echo property & Echo properties with uniform internal echo (homogeneous) versus uneven internal echo (heterogeneous). \\
Internal echo level & The solid part of the thyroid is evaluated by comparing it to the surrounding thyroid tissue. \\
Internal coarse calcification & Lesion contains coarse $(\geq 1 \mathrm{~mm}$ ) high echo findings. \\
Microcalcifications & Lesion contains fine (<1 mm) high echo findings. \\
Internal blood flow & The internal blood flow on color Doppler imaging is visible. \\
Boundary hypoechoic zone & A low echo band is visible at the boundary. \\
Nodule type & Solid (no cystic areas) versus mixed (solid and cystic areas). \\
\hline
\end{tabular}

between the pathological findings in the isolated thyroid gland and $\mathrm{TgAb} / \mathrm{TPOAb}$ levels measured in the patient's serum [12]. In this study, the cutoff values of TgAb and TPOAb levels for the diagnosis of Hashimoto's thyroiditis were 28 and $16 \mathrm{IU} / \mathrm{mL}$, respectively, and it was therefore concluded that Hashimoto's thyroiditis should be diagnosed at values of $\mathrm{TgAb} \geq 28 \mathrm{IU} / \mathrm{mL}$ and/or TPOAb $\geq 16 \mathrm{IU} / \mathrm{mL}[11,13]$. In Japan, these research results have been adopted into clinical practice; consequently, in this study we considered $\mathrm{TgAb} \geq 28 \mathrm{IU} / \mathrm{mL}$ and/or TPOAb $\geq 16 \mathrm{IU} / \mathrm{mL}$ to be outside the normal range, and therefore, an additional 82 patients were excluded. All 82 of the excluded patients had $\mathrm{TgAb} \geq 28 \mathrm{IU} / \mathrm{mL}$, and 32 of them had TPOAb $\geq$ $16 \mathrm{IU} / \mathrm{mL}$. No patients had an isolated abnormally high value of $\geq 16 \mathrm{IU} / \mathrm{mL}$. For analysis of the relationship between serum Tg concentration and nodule size, 34 patients with multiple nodules were excluded, leaving a total of 120 patients (104 patients, benign subgroup; 16 patients, malignant subgroup) to be included in this analysis.

\section{Researchers who performed image analysis and interpre- tation}

Three doctors specializing in endocrine diabetes internal medicine who are engaged in performing thyroid ultrasonography at Saitama Medical University participated in the image analysis. These doctors have an average of 10 years of experience. For all cases, at least two doctors performed image analysis and unified the evaluation of the ultrasound images.

\section{Evaluation method of ultrasonic test results}

All the ultrasonic diagnostic imaging devices used Hi vision Ascendus uniformly (Hitachi Ltd, Tokyo, Japan). For the ultrasonographic inspection, a probe including a high-frequency band of 9 - $15 \mathrm{MHz}$ was used. The blood flow inside the thyroid nodule was also evaluated using color Doppler.

The items evaluated by B-mode ultrasonography were thyroid volume, thyroid nodule volume, thyroid nodule prop- erties (solid or mixed (solid with cystic structures)), shape (arranged or irregular), boundary properties (smooth or coarse), boundary clarity (clear or unclear), boundary hypoechoic zone (regular, irregular or none), internal properties (uniform or non-uniform), internal echo level (isoechoic or hypoechoic), coarse internal calcification (presence or absence) and microcalcifications (presence or absence). Color Doppler was used to evaluate internal blood flow (abundant, small amount, or none) as shown in Table 1 and Figure 2. The microcalcifications and other evaluation items were classified according to the report of Kwak et al [14]. The volumes of the thyroid gland and nodules were calculated using the method used in Suzuki et al's study $[15,16]$. For thyroid volume (milliliters), the width, thickness and height of each lobe were measured, and the volume of each lobe was calculated using the mean of the elliptical shape volume formula $(\pi / 6 \times$ width $\times$ thickness $\times$ height) [15]. Thyroid nodule volume (milliliters) was calculated as follows: depth $(\mathrm{cm}) \times$ width $(\mathrm{cm}) \times$ length $(\mathrm{cm})$ $\times \pi / 6[16]$.

When the utility of measuring serum Tg concentration was examined, the difference in serum Tg levels between the benign and malignant subgroups was analyzed, and the value of the serum Tg value/nodule volume ratio was also analyzed in the same way.

\section{Statistical analyses}

Data were shown as mean \pm standard deviation or median (interquartile range), and missing values were excluded from the analysis. Pearson's $\chi^{2}$ test, Fisher's exact test and Welch's $t$-test were used for the analysis of the ultrasonography test results, and a $\mathrm{P}$ value of $<0.05$ was considered significant. In Pearson's $\chi^{2}$ test, the results of the comparisons among the three groups were evaluated using residual analysis. Residual analysis was used to determine which of the three groups had a significant difference in the observed values in the Pearson's $\chi^{2}$ test. It was confirmed that each item had a significant difference using the adjusted standardized residue value. Adjusted standardized residue value of $\geq 1.96$ or $\leq-1.96$ was considered significant. With regard to the ultrasonographic findings, the 


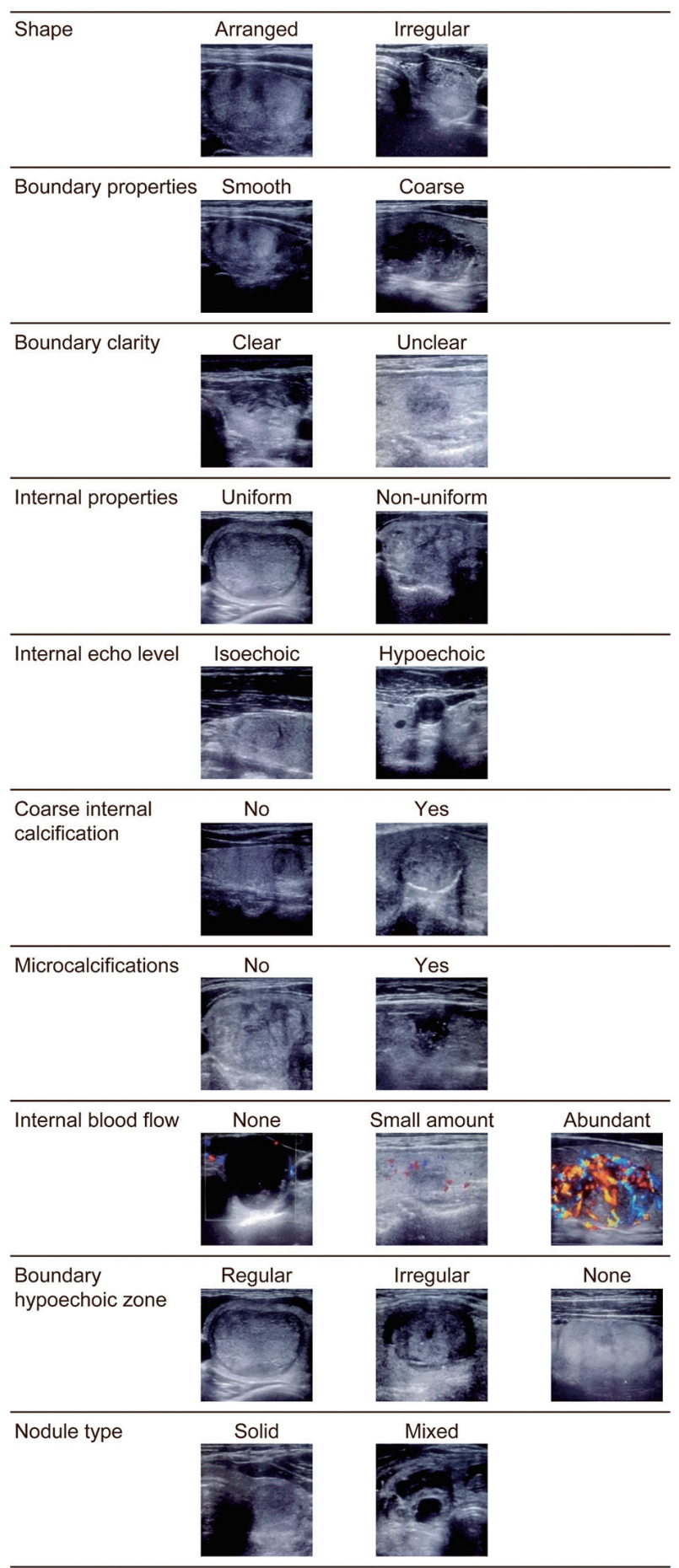

Figure 2. Transverse ultrasound image of thyroid nodules.

sensitivity, specificity and positive likelihood ratio were analyzed. Wilcoxon's test was used to compare the differences in serum $\mathrm{Tg}$ level and serum $\mathrm{Tg}$ /nodule volume ratio between the benign subgroup and malignant subgroup. Serum $\operatorname{TgAb}$ and TPOAb levels were also analyzed in the same way. All analyses were performed using SPSS statistics software package (IBM Corp., NY, USA).

\section{Results}

\section{Background of the study patients}

Table 2 shows the background of the study patients. The age of 26 patients with malignant nodules was $52.8 \pm 16.7$ years, while that of 210 patients with benign nodules was $60.2 \pm$ 13.4 years. The mean age was significantly lower in the malignant nodules group than in the benign nodules group $(\mathrm{P}<$ $0.05)$. In total, 11 men and 15 women had malignant nodules, whereas 46 men and 164 women had benign nodules. The proportion of men was significantly higher in the malignant nodules group than in the benign nodules group $(\mathrm{P}<0.05)$. Regarding the laboratory parameters, serum $\mathrm{Tg}, \mathrm{TgAb}$ and TPOAb levels were also shown in Table 2. Serum Tg concentration was $91.6(17.7-138.0) \mathrm{ng} / \mathrm{mL}$ in the malignant nodule group, and $52.4(20.8-114.6) \mathrm{ng} / \mathrm{mL}$ in the benign nodule group, and the TgAb level was $17.5(10.8-80.0) \mathrm{IU} / \mathrm{mL}$ in the malignant nodule group and $15.0(10.0-34.0) \mathrm{IU} / \mathrm{mL}$ in the benign nodule group. The TPOAb level was 7.5 (5.8 - 11.0) $\mathrm{IU} / \mathrm{mL}$ in the malignant nodule group, and $8.0(6.0-11.0) \mathrm{IU} /$ $\mathrm{mL}$ in the benign nodule group. Serum $\mathrm{Tg}, \mathrm{TgAb}$ and $\mathrm{TPOAb}$ levels did not differ significantly between the benign and malignant groups.

\section{Differentiating benign and malignant based on ultrasonog- raphy results}

The results are shown in Table 3. Thyroid volume was 37.3 $\pm 27.3 \mathrm{~mL}$ in the benign nodule group and $25.5 \pm 11.0 \mathrm{~mL}$ in the malignant nodule group, and the thyroid volume was significantly smaller in the malignant nodule group $(\mathrm{P}<0.01)$. Moreover, the volume of benign thyroid nodules was $11.7 \pm$ $7.1 \mathrm{~mL}$ and that of malignant thyroid nodules was $3.9 \pm 2.4$ $\mathrm{mL}$. The malignant nodule was significantly smaller than the benign nodule $(\mathrm{P}<0.01)$. Malignant thyroid nodules showed significantly lower echoes than benign nodules $(\mathrm{P}<0.01)$. With regard to internal microcalcifications, malignant nodules showed significantly more microcalcifications than benign nodules $(\mathrm{P}<0.01)$. With regard to internal blood flow findings, nodules rich in blood flow seemed to be malignant, while nodules with no blood flow seemed to be benign $(\mathrm{P}<0.05)$. With regard to nodule type, solid nodules suggested malignant nodules and mixed nodules suggested benign nodules $(\mathrm{P}<$ 0.01 ). There was no significant difference between the benign and malignant nodules in the low-echo band at the boundary (regular, irregular, or none), shape (arranged or irregular), boundary property (smooth or coarse), boundary clarity (clear or unclear), internal echo property (uniform or non-uniform) and internal coarse calcification (presence or absence). Table 4 shows the inspection accuracy of the ultrasonographic findings. The sensitivity, specificity and positive likelihood ratio of internal echo level (hypoechoic) were 53.1\%, 68.1\% and 1.67 , respectively. With regard to internal microcalcifications, the sensitivity, specificity and positive likelihood ratio were $62.5 \%, 75.9 \%$ and 2.6 , respectively. 
Table 2. Profiles of Patients With Thyroid Nodules

\begin{tabular}{|c|c|c|c|c|}
\hline & $\begin{array}{l}\text { Total ( } 331 \text { nodules, } \\
236 \text { patients) }\end{array}$ & $\begin{array}{l}\text { Malignant nodules (33 } \\
\text { nodules, } 26 \text { patients) }\end{array}$ & $\begin{array}{l}\text { Benign nodules ( } 298 \\
\text { nodules, } 210 \text { patients) }\end{array}$ & P-value* \\
\hline Age, years & $59.4 \pm 13.9$ & $52.8 \pm 16.7$ & $60.2 \pm 13.4$ & $<0.05^{\dagger}$ \\
\hline Sex, n (male/female) & $57 / 179$ & $11 / 15$ & $46 / 164$ & $<0.05^{\dagger}$ \\
\hline BMI, $\mathrm{kg} / \mathrm{m}^{2}$ & $23.6 \pm 4.2$ & $24.2 \pm 4.1$ & $23.5 \pm 4.2$ & $0.45^{\dagger}$ \\
\hline History of thyroid disease, n (yes/no/unknown) & $18 / 215 / 3$ & $0 / 25 / 1$ & $18 / 190 / 2$ & $0.12 \ddagger$ \\
\hline $\mathrm{Tg}, \mathrm{ng} / \mathrm{mL}$ & $55.3(20.8-115.6)$ & $91.6(17.7-138.0)$ & $52.4(20.8-114.6)$ & $0.42^{\S}$ \\
\hline $\mathrm{TgAb}, \mathrm{IU} / \mathrm{mL}$ & $15.0(10.0-35.0)$ & $17.5(10.8-80.0)$ & $15.0(10.0-34.0)$ & $0.44 \S$ \\
\hline $\mathrm{TPOAb}, \mathrm{IU} / \mathrm{mL}$ & $8.0(6.0-11.0)$ & $7.5(5.8-11.0)$ & $8.0(6.0-11.0)$ & $0.99^{\S}$ \\
\hline
\end{tabular}

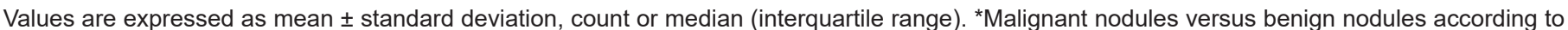

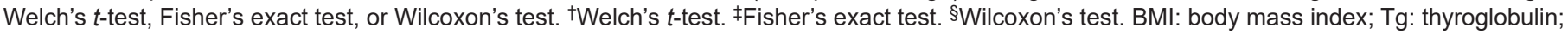
TgAb: anti-thyroglobulin antibody; TPOAb: anti-thyroid peroxidase antibody.

\section{Usefulness of serum $\mathrm{Tg}$ concentration measurement in be- nign and malignant nodule differentiation}

After examining the subgroup of patients with a single nodule and those who tested negative for $\operatorname{TgAb}$, the median (interquartile range) serum $\mathrm{Tg}$ concentration was 32.7 (11.0 - 83.8) $\mathrm{ng} / \mathrm{mL}$ in the subgroup of patients with benign nodules and $104.5(22.6$ - 182.0) $\mathrm{ng} / \mathrm{mL}$ in the subgroup of patients with malignant nodules. Serum Tg values were not significantly different between the two subgroups. Serum Tg was significantly positively correlated with nodule volume $(\mathrm{r}=0.40, \mathrm{P}$ $<0.0001)$. Based on this result, we compared the serum Tg value/nodule volume ratios between the two subgroups (Fig. 3 ). The serum Tg value/nodule volume ratio, expressed as median (interquartile range), was 13.3 (4.2 - 51.3) in the benign nodule subgroup and 29.7 (15.0 - 340.6) in the malignant nodule subgroup. When compared between these subgroups, the serum $\mathrm{Tg} /$ nodule volume ratio was significantly higher in the subgroup of patients with malignant nodules than in the subgroup of patients with benign nodules $(\mathrm{P}<0.05)$.

\section{Discussion}

In recent years, the incidence of differentiated thyroid cancer has increased dramatically around the world, and a Korean study in 2014 confirmed a 15-fold increase in the incidence from 1993 to 2011 [4]. One reason for this is that cancer screening in Korea is offered free of charge, but it is also owing to the fact that the ultrasound diagnostic device can obtain higher-resolution images. On the contrary, the mortality rate remains low, and it is necessary to reconsider the diagnosis process for the possibility of overdiagnosis.

For thyroid cancer, if a thyroid nodule is suspected by palpation, puncture aspiration cytology is performed directly without performing ultrasonography. However, at present, thyroid ultrasonography is performed first, and puncture aspiration cytology is only performed when necessary. When thy- roid nodule lesions are observed, thyroid nodules are evaluated based on the ultrasound diagnostic criteria in order to differentiate benign from malignant nodules $[17,18]$. In addition, several previous studies have reported the thyroid ultrasonographic findings of patients with PTC [17-20]. However, there is no Japanese study in which two or more doctors interpret and evaluate the same case using a uniform ultrasonography system. We used this method to classify the nodule properties based on the abovementioned items by discussing each one with all the readers and selecting similar findings, so that classification was made more accurately.

In the present study, hypoechoic nodules, presence of microcalcification and solid nodules suggested malignant nodules in B-mode images of nodules, and findings of abundant internal blood flow using color Doppler tests (Table 3) also indicated malignancy. In addition, malignant nodules had significantly higher serum $\mathrm{Tg} /$ volume ratios than benign nodules (Fig. 3). However, no clear cutoff value could be suggested; thus, the utility of measuring serum $\mathrm{Tg}$ /volume of nodule ratio in clinical practice remains questionable. With regard to the findings of B-mode images, the diagnosis of PTC could be further enhanced if multiple findings suggesting the abovementioned malignant nodules are observed. Using B-mode ultrasound to confirm the presence of nodules and to determine presence or absence of the abovementioned findings is a useful method for differentiating PTC from many benign nodules in actual clinical practice. Bastin et al reported that B-mode images may show microcalcifications that are unclear or lobulated; increased blood flow in the nodule; aspect ratio $>1$; solid nodules; and low-echo nodules [5]. In Japan, Shimura et al reported that the nodule shape, internal echo level and nodule boundary were considered useful findings suggesting malignancy, and that there was no significant difference in microcalcifications [20]. With regard to microcalcifications, the results of B-mode imaging examinations differed depending on the study and are regarded as minor findings based on the ultrasound diagnostic criteria for thyroid nodules in Japan [21]. In this study, however, the presence of microcalcifications suggested malignancy, and it was considered to be a useful finding 
Table 3. Comparison of Ultrasonography Results Between Benign and Malignant Nodules

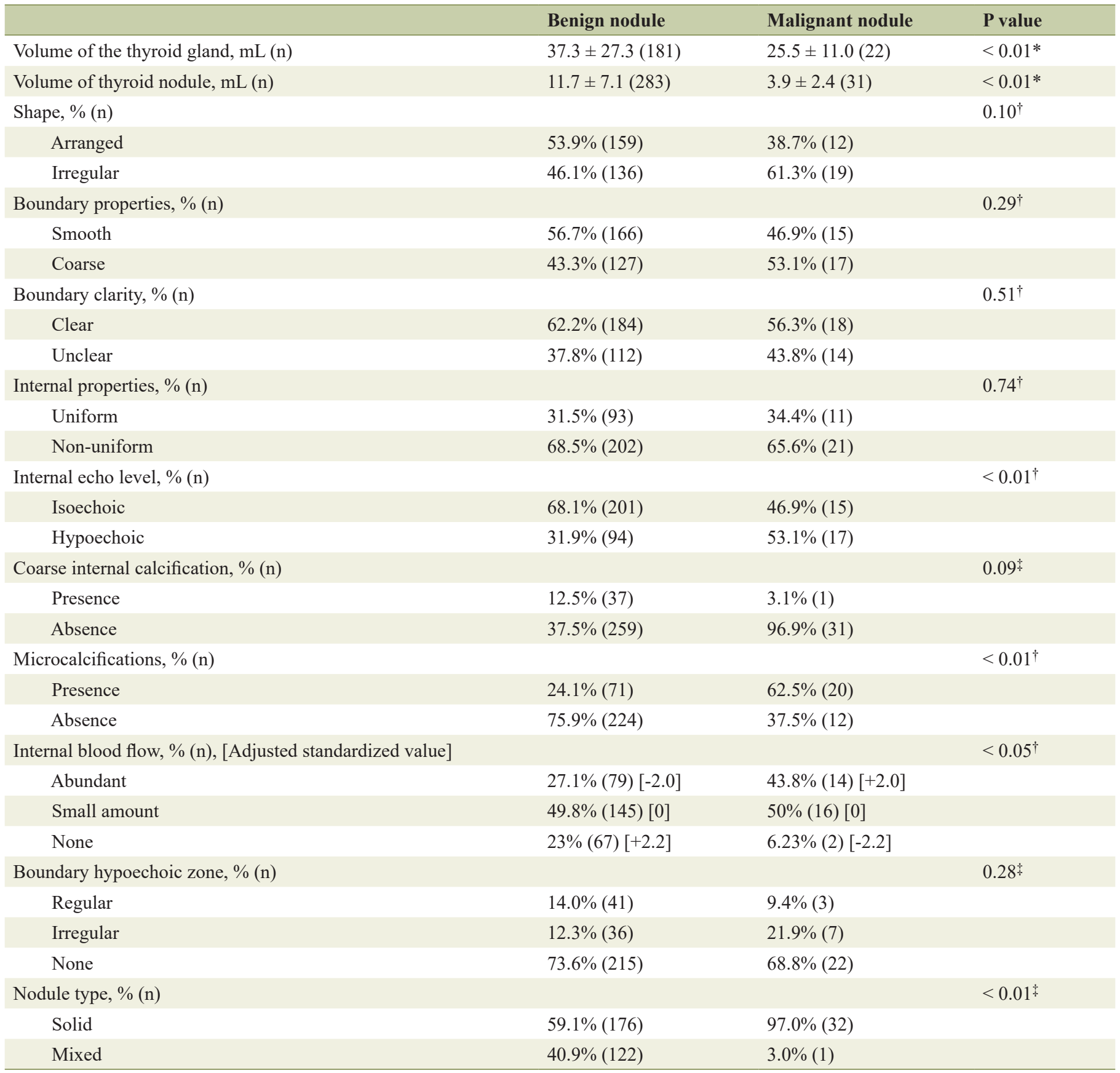

Values of the thyroid gland and nodule are expressed as mean \pm standard deviation. *Welch's $t$-test. 'Pearson's $X^{2}$ test. ${ }^{\ddagger}$ Fisher's exact test.

to determine papillary cancer.

With regard to blood flow, many of the currently used ultrasonic diagnostic apparatuses have a color Doppler function and can be used at the screening stage. Previous studies have examined the prediction of malignant findings combining the B-mode and Doppler methods. Frates et al reported that color Doppler findings were subdivided into 0 - 5 stages, and blood-rich nodules were common in patients with malignant nodules [22]. Appetecchia et al reported that color Dop- pler studies were divided into types I-III in terms of blood flow findings, and that nodules rich in internal blood flow comprised mainly of malignant nodules [23]. These results are consistent with the results of this study. On the contrary, Moon et al reported that blood flow in the nodule was detected even in benign nodules. Therefore, color Doppler is not superior to B-mode imaging. Moreover, the Korean Radiological Society consensus statement also reported that the use of color Doppler during normal examinations is not recom- 
Table 4. Diagnostic Accuracy of the Ultrasonographic Findings

\begin{tabular}{llll}
\hline & Sensitivity (\%) & Specificity (\%) & Positive likelihood ratio \\
\hline Internal echo level (hypoechoic) & 53.1 & 68.1 & 1.67 \\
Microcalcifications (presence) & 62.5 & 75.9 & 2.6 \\
Internal blood flow (abundant) & 43.8 & 72.9 & 1.61 \\
Nodule type (solid) & 96.9 & 41.4 & 1.65 \\
\hline
\end{tabular}

mended $[24,25]$. However, based on the results of this study, the combination of B-mode imaging results and color Doppler findings may prove to be a useful tool for distinguishing PTC from benign lesions.

Horvath et al proposed the Thyroid Imaging Reporting and Data System (TIRADS) as a useful thyroid ultrasound diagnostic system [26]. We considered TIRADS to be a breakthrough system that can confirm malignant tumors by combining multiple echo findings. In addition, TIRADS was evaluated in a prospective study as well as in a meta-analysis [27, 28]. However, based on the results of these studies, TIRADS was considered to be ineffective in Japan [29]. This may be due to the differences in thyroid tumor ultrasound findings between patients in the US and Europe, who were the subjects in TIRADS studies, and patients in Japan. In the present study, the diagnostic accuracy of ultrasonographic findings was analyzed. Although the individual findings were not very sensitive or specific, it was thought that combining multiple findings would be useful for diagnosis. In future studies, we hope to increase the sample size and establish a similar system appropriate for the Japanese patient cohort.

Serum Tg measurement is currently not considered use- ful for distinguishing benign nodules from malignant thyroid nodules [6]. Serum Tg levels are thought to increase with increasing nodule size, both in benign and malignant nodules [30]. Our study also showed a significant positive correlation between serum Tg and nodule volume in 120 patients with benign or malignant single nodules and those who tested negative for $\operatorname{TgAb}(\mathrm{P}<0.05)$. Therefore, we calculated the value of serum $\mathrm{Tg} /$ nodule volume ratio and compared the results between benign and malignant nodules in order to determine the influence of serum $\mathrm{Tg}$ value. We speculated that if the measurement of serum $\mathrm{Tg}$ /nodule volume ratio is useful for differentiating benign from malignant nodules, it could be easily calculated even in the actual clinical setting; therefore, it was considered a very good discrimination method. The results of the comparative study showed a significant difference in the value of serum $\mathrm{Tg} /$ nodule volume ratio between benign and malignant nodules. However, this parameter cannot be used to differentiate between benign and malignant in actual clinical practice. Future studies incorporating a larger sample size and prospective study design will be required to further validate our results and determine whether serum $\mathrm{Tg}$ /nodule volume ratios can serve

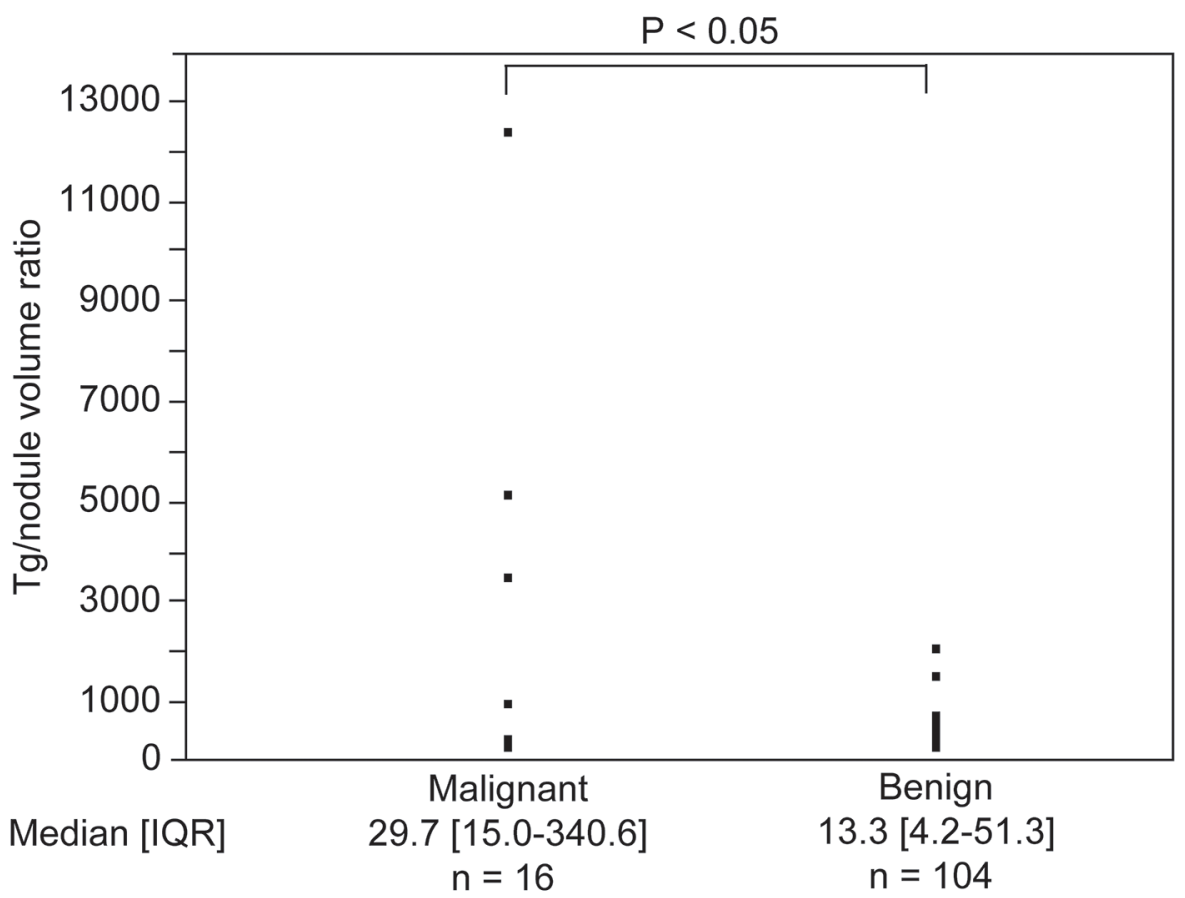

Figure 3. Difference in the value of serum thyroglobulin $(\mathrm{Tg}) /$ nodule volume ratios between the malignant and benign nodule groups. IQR: interquartile range. 
as a useful diagnostic aid.

This study has some limitations. If thyroid ultrasound is performed and thyroid nodules suspected of lymph node metastasis are observed or if there is a sudden increase in thyroid nodules in a short period of time, a thyroid puncture should be considered by the attending physician. Aspiration cytology was not performed in our department, and some patients were directly referred for thyroid surgery, and thus, were excluded from this study. In the present study, when investigating ultrasonographic findings, we did not investigate the evaluation by detailed categories; that is, by the evaluation of intermediate existence, such as mild and moderate, and we evaluated only in the two categories of presence and absence. This was because we wanted to conduct a survey using the simplest evaluation method possible and to identify an evaluation that is easy to use in actual clinical situations. However, it is very important to conduct detailed evaluation by category as mentioned above, and we are considering increasing the sample size in the future to investigate this by such a detailed categorical study. There may also be a bias in this study due to missing values of the thyroid ultrasonography findings. In addition, the number of patients with thyroid cancer other than PTC was small, and thus, meaningful statistical analysis could not be performed in these patients.

\section{Conclusions}

In the present study, we examined the findings of B-mode and color Doppler ultrasonography for thyroid nodules. In Bmode, the thyroid nodule was hypoechoic, showed microcalcification and was a solid nodule suggesting malignancy. In color Doppler examination, the blood flow inside the nodules was abundant, suggesting malignancy. By combining these image findings, in the diagnosis of PTC, it is possible to reduce the number of unnecessary invasive FNAC examinations and to consider PTC as an easy and cost-effective method. In the future, we intend to further increase the number of target patients and use ultrasound imaging to investigate findings that suggest malignant nodules. We will investigate not only PTC but also other thyroid cancers to determine how combining the findings that suggest malignancy on the ultrasound image can improve the cancer diagnosis rate.

\section{Acknowledgments}

The authors would like to express their gratitude to Kazuyuki Inoue, $\mathrm{MD}$, for his role in the data collection. We would also like to thank Ikuo Inoue, $\mathrm{MD}, \mathrm{PhD}$, Mitsuhiko Noda, MD, $\mathrm{PhD}$, and Akira Shimada, $\mathrm{MD}, \mathrm{PhD}$, for discussing some aspects of the manuscript.

\section{Financial Disclosure}

This research received the 2017 Young Researcher Training Research Fund (Saitama Medical University).

\section{Conflict of Interest}

The authors declare that they have no conflict of interest.

\section{Informed Consent}

Informed consent was obtained from all participants.

\section{Author Contributions}

DS and SY conceptualized and designed the study, collected the data, conducted initial analyses and drafted the initial manuscript. RN collected the data, SY and RN critically reviewed the manuscript and SY approved the final manuscript as submitted.

\section{Data Availability}

The authors declare that data supporting the findings of this study are available within the article.

\section{References}

1. Yanohara K, Takahashi Y, Kato A. Ultrasonographic examination of thyroid tumor in human dry dock. Japanese Jornal of Head and Neck Cancer. 1991;17(2):117-121. Japanese.

2. Ishida T, Izuo M, Ogawa T, Kurebayashi J, Satoh K. Evaluation of mass screening for thyroid cancer. Jpn J Clin Oncol. 1988;18(4):289-295.

3. Shimura H. Data from frequency and course - multiphasic health screening of thyroid neoplasms in Japan. Journal of the Japan Thyroid Association. 2010;1(2):109-113 (in Japanese).

4. Ahn HS, Kim HJ, Welch HG. Korea's thyroid-cancer "epidemic" - screening and overdiagnosis. N Engl J Med. 2014;371(19):1765-1767.

5. Bastin S, Bolland MJ, Croxson MS. Role of ultrasound in the assessment of nodular thyroid disease. J Med Imaging Radiat Oncol. 2009;53(2):177-187.

6. Haugen BR, Alexander EK, Bible KC, Doherty GM, Mandel SJ, Nikiforov YE, Pacini F, et al. 2015 American Thyroid Association Management Guidelines for adult patients with thyroid nodules and differentiated thyroid cancer: the American Thyroid Association Guidelines Task Force on thyroid nodules and differentiated thyroid cancer. Thyroid. 2016;26(1):1-133.

7. Michikawa T, Inoue M, Shimazu T, Sawada N, Iwasaki M, Sasazuki S, Yamaji T, et al. Seaweed consumption and the risk of thyroid cancer in women: the Japan Public Health Center-based Prospective Study. Eur J Cancer Prev. 2012;21(3):254-260.

8. Nakamura H. [Management for thyroid nodules]. Nihon Rinsho. 2012;70(11):1872-1879.

9. The Japanese Society of Thyroid Surgery. General rules 
for the description of thyroid cancer. 7 th ed. Tokyo: Kanehara \& Co., Ltd, 2015:54-56 (In Japanese).

10. Ali S, Cibas E. The Bethesda system for reporting thyroid cytopathology: definitions, criteria, and explanatory notes. 2nd ed. New York: Springer, 2018:1-18.

11. Takasu N, Yoshimura Noh J. Hashimoto's thyroiditis: TGAb, TPOAb, TRAb and recovery from hypothyroidism. Expert Rev Clin Immunol. 2008;4(2):221-237.

12. Morita S, Nishihara E, Kubota S, Hukada S, Hirokawa M, Amino N, Miyauchi A, et al. Evaluation of anti-thyroglobulin antibody kit "Elecsys Anti-Tg" and anti thyroid peroxidase antibody kit "Elecsys Anti-TPO" - Comparison with cut off value using ROC curve and present method. Igaku To Yakugaku. 2006;55(5):775-782 (In Japanese).

13. Furuya M, Yada S, Yokomura M, Hosoda E, Tomoda M, Miura H. Basic evaluation of thyroid test by electrochemiluminescence immunoassay system "cobas8000 e801 module". Igaku To Yakugaku. 2017;74(3):316-326 (In Japanese).

14. Kwak JY, Han KH, Yoon JH, Moon HJ, Son EJ, Park SH, Jung HK, et al. Thyroid imaging reporting and data system for US features of nodules: a step in establishing better stratification of cancer risk. Radiology. 2011;260(3):892899.

15. Suzuki S, Midorikawa S, Fukushima T, Shimura H, Ohira T, Ohtsuru A, Abe M, et al. Systematic determination of thyroid volume by ultrasound examination from infancy to adolescence in Japan: the Fukushima Health Management Survey. Endocr J. 2015;62(3):261-268.

16. Knudsen N, Bols B, Bulow I, Jorgensen T, Perrild H, Ovesen L, Laurberg P. Validation of ultrasonography of the thyroid gland for epidemiological purposes. Thyroid. 1999;9(11):1069-1074.

17. Smith-Bindman R, Lebda P, Feldstein VA, Sellami D, Goldstein RB, Brasic N, Jin C, et al. Risk of thyroid cancer based on thyroid ultrasound imaging characteristics: results of a population-based study. JAMA Intern Med. 2013;173(19):1788-1796.

18. Brito JP, Gionfriddo MR, Al Nofal A, Boehmer KR, Leppin AL, Reading C, Callstrom M, et al. The accuracy of thyroid nodule ultrasound to predict thyroid cancer: systematic review and meta-analysis. J Clin Endocrinol Metab. 2014;99(4):1253-1263.

19. Suzuki S, Bogdanova TI, Saenko VA, Hashimoto Y, Ito M, Iwadate M, Rogounovitch TI, et al. Histopathological analysis of papillary thyroid carcinoma detected during ultrasound screening examinations in Fukushima. Cancer Sci. 2019;110(2):817-827.
20. Shimura H, Haraguchi K, Hiejima Y, Fukunari N, Fujimoto Y, Katagiri M, Koyanagi N, et al. Distinct diagnostic criteria for ultrasonographic examination of papillary thyroid carcinoma: a multicenter study. Thyroid. 2005;15(3):251-258.

21. Kitaoka M, Miyamoto Y, Fukunari N, Omoto K, Kameyama K, Kobayashi K. Draft of ultrasound diagnostic criteria for thyroid nodule. Jpn J Med Ultrasonics. 2011;38(6):667-670 (In Japanese).

22. Frates MC, Benson CB, Doubilet PM, Cibas ES, Marqusee E. Can color Doppler sonography aid in the prediction of malignancy of thyroid nodules? J Ultrasound Med. 2003;22(2):127-131; quiz 132-124.

23. Appetecchia M, Solivetti FM. The association of colour flow Doppler sonography and conventional ultrasonography improves the diagnosis of thyroid carcinoma. Horm Res. 2006;66(5):249-256.

24. Moon HJ, Kwak JY, Kim MJ, Son EJ, Kim EK. Can vascularity at power Doppler US help predict thyroid malignancy? Radiology. 2010;255(1):260-269.

25. Moon WJ, Baek JH, Jung SL, Kim DW, Kim EK, Kim JY, Kwak JY, et al. Ultrasonography and the ultrasound-based management of thyroid nodules: consensus statement and recommendations. Korean J Radiol. 2011;12(1):1-14.

26. Horvath E, Majlis S, Rossi R, Franco C, Niedmann JP, Castro A, Dominguez M. An ultrasonogram reporting system for thyroid nodules stratifying cancer risk for clinical management. J Clin Endocrinol Metab. 2009;94(5):17481751.

27. Horvath E, Silva CF, Majlis S, Rodriguez I, Skoknic V, Castro A, Rojas H, et al. Prospective validation of the ultrasound based TIRADS (Thyroid Imaging Reporting And Data System) classification: results in surgically resected thyroid nodules. Eur Radiol. 2017;27(6):26192628.

28. Wei X, Li Y, Zhang S, Gao M. Meta-analysis of thyroid imaging reporting and data system in the ultrasonographic diagnosis of 10,437 thyroid nodules. Head Neck. 2016;38(2):309-315.

29. Sunny SS, Hephzibah J, Mathew D, Bondu JD, Shanthly N, Oommen R. Stimulated serum thyroglobulin levels versus unstimulated serum thyroglobulin in the follow-up of patients with papillary thyroid carcinoma. World J Nucl Med. 2018;17(1):41-45.

30. Suh I, Vriens MR, Guerrero MA, Griffin A, Shen WT, Duh QY, Clark OH, et al. Serum thyroglobulin is a poor diagnostic biomarker of malignancy in follicular and Hurthle-cell neoplasms of the thyroid. Am J Surg. 2010;200(1):41-46. 